\title{
Terapia ocupacional na Atenção Primária à Saúde: reflexóes sobre as populaçóes atendidas
}

\author{
Fernanda Reis ${ }^{a}$, Mariana Leme Gomes ${ }^{b}$, Marta Aoki $^{c}$ \\ aTerapeuta Ocupacional, Especialista com caráter de Residência Multiprofissional em Saúde da Família e \\ Comunidade, Mestranda em Saúde Pública, Universidade Federal do Ceará - UFC, Fortaleza, CE, Brasil

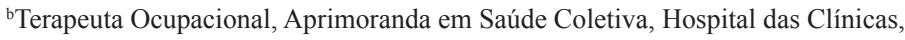 \\ Faculdade de Medicina, Universidade de São Paulo - USP, São Paulo, SP, Brasil \\ ${ }^{\mathrm{c}}$ Mestre em Ciências da Reabilitação, Faculdade de Medicina, Terapeuta Ocupacional, \\ Laboratório de Reabilitação com Ênfase no Território, Departamento de Fisioterapia, \\ Fonoaudiologia e Terapia Ocupacional, Universidade de São Paulo - USP, São Paulo, SP, Brasil
}

\begin{abstract}
Resumo: Este trabalho é fruto das reflexões de um grupo de discussão entre profissionais, estudantes e docentes realizado durante o I Simpósio de Terapia Ocupacional na Atenção Primária à Saúde (APS), em 2011, o qual teve como objetivo refletir sobre questões relacionadas às populações assistidas pelo terapeuta ocupacional na APS. As discussões realizadas indicaram dois eixos de reflexão: (1) os desafios na composição das linhas de cuidado e as condições de vida da população atendida pela terapia ocupacional; (2) a prática generalista do terapeuta ocupacional e a inserção em equipes interdisciplinares. Os participantes relataram que na APS realizam a atenção a populações tradicionalmente acompanhadas pela terapia ocupacional como pessoas em sofrimento psíquico, pessoas com deficiências, crianças com atraso do desenvolvimento, entre outras. A discussão apontou que a dificuldade de acesso aos serviços, a fragilidade na constituição das linhas de cuidado integral à saúde e a negligência dos serviços a uma série de grupos excluídos do cuidado são definidoras do perfil da população acompanhada e das potencialidades da atenção, fatores relacionados à constituição da APS e do Sistema Único de Saúde (SUS) no país. Por outro lado, as condições de vida da população atendida, marcadas por situações de pobreza e exclusão social, a fragmentação das práticas na APS e a necessidade de que o profissional tenha um perfil generalista, capaz de atuar de forma interdisciplinar e intersetorial, foram consideradas fundamentais para a construção de novas ferramentas de trabalho, para o aperfeiçoamento teórico e maior fundamentação da atuação profissional na APS.
\end{abstract}

Palavras-chave: Terapia Ocupacional, Atenção Primária à Saúde, Pessoas com Deficiência, Saúde Mental, Formação de Recursos Humanos.

\section{Occupational Therapy in Primary Health Care: reflections on the populations assisted}

\begin{abstract}
This work is the result of reflections of a group discussion among professionals, students and teachers held during the First Symposium on Occupational Therapy in Primary Health Care (PHC) in 2011, which aimed to reflect on issues related to the populations assisted by the occupational therapist in PHC. The discussions suggested two areas of consideration: (1) the challenges in the composition of care lines as well as living conditions of the population assisted by occupational therapy; (2) the general practice of occupational therapists and their inclusion in interdisciplinary teams. Participants reported that, in PHC, they provide assistance to populations traditionally accompanied by Occupational Therapy such as people under psychological distress, people with
\end{abstract}

Autor para correspondência: Fernanda Reis, Universidade Federal do Ceará, Rua Professor Costa Mendes, 1608, Bloco Didático, $5^{\circ}$ andar, Rodolfo Teófilo, CEP 60430-140, Fortaleza, CE, Brasil, e-mail: fernandareis_to@yahoo.com.br

Recebido em 8/8/2012; Aceito em 10/9/2012. 
disabilities, children with developmental delay, among others. The discussion pointed out that the difficulty of access to services, the weakness in the constitution of the lines of comprehensive health care and neglect of services to a number of groups that are excluded from care, define the profile of the population monitored and the potential of assistance. These factors are related to the formation of PHC and "SUS" (Brazilian Health System) in the country. On the other hand, the living conditions of the population assisted, marked by poverty and social exclusion, the fragmentation of PHC practices, and the need for the professional to have a generalist profile, being able to act interdisciplinarily and intersectorally, were considered crucial for the construction of new working tolls, theoretical improvement, and greater theoretical basis of professional performance in PHC.

Keywords: Occupational Therapy, Primary Health Care, Disabled Person, Mental Health, Human Resources Education.

\section{Introdução}

Esse trabalho é fruto das reflexóes de estudantes, profissionais e docentes de Terapia Ocupacional que participaram de um grupo de discussão realizado no I Simpósio de Terapia Ocupacional na Atençáo Primária a Saúde - XII Congresso Brasileiro e IX Congresso Latino Americano de Terapia Ocupacional, em outubro de 2011, na cidade de São Paulo.

O grupo de trabalho teve como objetivo discutir e refletir sobre a intervenção do terapeuta ocupacional na Atenção Primária à Saúde (APS), tendo como foco as populações assistidas pelo profissional e suas principais questóes. Estiveram presentes no debate 26 pessoas que se interessaram pelo tema, dentre estudantes, profissionais que atuavam na Atenção Primária à Saúde e docentes de Terapia Ocupacional de diversas regiōes do país. A discussão foi baseada em texto produzido pelas coordenadoras do grupo, no qual foram descritas brevemente as populaçôes atendidas pela terapia ocupacional, bem como a articulaçáo da assistência em linhas de cuidado, de acordo com documento do Ministério da Saúde relacionado às açōes na APS (BRASIL, 2010a).

As discussóes realizadas foram registradas e, a partir desta memória, pôde-se recuperar as principais questóes trazidas pelos participantes do grupo e assim possibilitar as reflexóes apresentadas neste texto.

Em geral, os profissionais reconheceram que há necessidade de atenção às populaçóes com demandas específicas. Nesse sentido, foram apresentadas como população tradicionalmente atendida pela terapia ocupacional na APS as pessoas em sofrimento psíquico, pessoas com deficiências, pacientes com sequelas de acidente vascular encefálico, crianças com atraso do desenvolvimento neuropsicomotor, idosos, entre outros grupos.

No entanto, a discussão não se deu a partir da focalização e diferenciação dessas populaçôes do ponto de vista de seu processo de adoecimento ou de necessidades de cuidado específicos, pelo contrário, foram abordados temas transversais, inerentes às diversas populações atendidas como, por exemplo, a preocupação a respeito da fragmentação das práticas de terapia ocupacional na APS, as condiçóes de vida da população atendida, a dificuldade da população no acesso a serviços de Atenção Primária à Saúde, a fragilidade na constituição das linhas de cuidado integral à saúde e a negligência dos serviços a uma série de grupos excluídos do cuidado à saúde, como indígenas, pessoas em situação de rua e trabalhadores.

Para melhor apresentação e aprofundamento das questóes levantadas, optou-se por organizar o presente texto a partir de uma breve caracterização das populaçóes atendidas pela terapia ocupacional na APS, seguida pela apresentação das discussóes realizadas pelo grupo de trabalho a partir de dois temas centrais:

- A fragilidade na composição da linha de cuidado no que se refere ao acesso à rede de serviços de referência e contrarreferência e a complexidade das demandas e necessidades de saúde apresentadas pela população atendida pela terapia ocupacional; e

- Os desafios e potencialidades na constituição do trabalho do terapeuta ocupacional generalista e em parceria com a equipe interdisciplinar.

\section{Atenção Primária à Saúde e as populações tradicionalmente acompanhadas pela terapia ocupacional: breve contextualização}

A Atenção Primária à Saúde é modalidade de atenção concebida na Conferência Internacional sobre Cuidados Primários de Saúde de Alma Ata. A APS deve constituir a principal porta de entrada do sistema de saúde e tem como atributos: a continuidade, a 
integralidade, a coordenação, a centralidade na família, a orientação para a comunidade e a adequação cultural na atenção à saúde (STARFIELD, 2002).

A APS foi introduzida nos países numa perspectiva seletiva e focalizada, principalmente como estratégia para controle de doenças, constituída por um pacote de intervenções de baixo custo. As açóes tinham como população alvo, principalmente, crianças e mulheres, com intervençôes no acompanhamento do crescimento, programas de reidratação oral, aleitamento materno, imunização, alfabetização feminina e planejamento familiar. Tal abordagem, mundialmente hegemônica e imposta pelos organismos internacionais de financiamento, foi amplamente criticada, principalmente por náo considerar os fatores socioeconômicos que influenciam na garantia de acesso à satisfação de necessidades básicas das populaçôes e que são determinantes para a condição de saúde das pessoas (GIOVANELLA; MENDONÇA, 2008).

No Brasil, a APS teve alguns momentos significativos na sua implantação, com o movimento pela Reforma Sanitária Brasileira, desde a década de 1970. Esse período foi caracterizado pela luta de movimentos sociais que também propuseram a reorganização dos serviços básicos de saúde e reivindicaram maior proteção social, tendo como cenário o processo de redemocratização do país. Tais mobilizaçôes culminaram na proposição e implantação do Sistema Único de Saúde (SUS), integrado à Constituiçãao Federal de 1988, que assegurou legalmente a assistência à saúde como direito de todos os cidadáos.

Na década de 1980 há referências sobre Açóes Integradas de Saúde na rede de serviços básicos voltados a populaçóes como idosos, adolescentes, portadores de doenças crônicas como hipertensáo, diabetes, entre outras, inclusive com a continuidade no estabelecimento de programas verticalizados de atenção a esses e outros grupos, como pessoas com tuberculose, hanseníase ou, ainda, em sofrimento psíquico.

Outro marco recente para o estabelecimento da APS foi a normatização do Programa de Saúde da Família, em 1996, e posteriormente a Estratégia de Saúde da Família (ESF), que orientaram a organizaçáo dos serviços locais segundo campos de atenção assistencial, de açóes ambientais e intersetoriais, tendo uma concepção de atenção à saúde ampliada e com vistas à integralidade. A ESF encerra em sua concepção mudanças importantes na dimensão organizacional do modelo assistencial ao constituir a Equipe de Saúde de Família multiprofissional e responsável pela atenção à saúde da população de um dado território, ao definir o generalista como o profissional médico da atenção básica e ao instituir os agentes comunitários de saúde (ACS) como profissionais mais próximos da comunidade, ampliando assim a atuação da equipe sobre os determinantes mais gerais do processo saúde-doença (GIOVANELLA; MENDONÇA, 2008).

Nesse processo, observou-se que a Estratégia de Saúde da Família incorporou outras populaçóes como foco da assistência, que anteriormente era voltada ao acompanhamento seletivo de crianças e mulheres e ao cuidado de patologias específicas. Atualmente, de acordo com a Política Nacional de Atenção Básica, deve-se oferecer cuidado também às pessoas em sofrimento psíquico, pessoas com deficiência, idosos, adolescentes, além da maior sistematização de programas já presentes na APS, como o acompanhamento de pessoas com diabetes, hipertensão arterial sistêmica, hanseníase e tuberculose. Observou-se também a ampliação das possibilidades de situaçóes abordadas, como é o caso do uso abusivo de álcool e outras drogas, a condição da violência, a promoção da participação social, dentre outros temas relacionados ao contexto histórico atual (BRASIL, 2006).

É neste cenário de ampliação das açôes da APS que se pretende discutir a intervenção do terapeuta ocupacional, tendo como foco as principais questôes apresentadas pela população assistida, a partir da percepção dos profissionais que participaram do grupo de discussão no Simpósio de Terapia Ocupacional na Atenção Primária à Saúde.

O resgate histórico da atuação do terapeuta ocupacional no Sistema Único de Saúde e especialmente na APS apontou alguns estudos importantes. Segundo Lopes (1999), a história do desenvolvimento da terapia ocupacional no estado de São Paulo, desde o final dos anos 1970, está intimamente ligada à própria história da expansão do ensino universitário, do emprego em saúde e dos serviços públicos neste setor, notadamente na área da assistência em saúde mental.

Oliver, Barros e Lopes (2005) afirmam que os terapeutas ocupacionais tiveram participaçáo ativa na proposiçáo de políticas públicas de saúde, sendo um dos profissionais que apoiaram os movimentos sociais na reivindicação do acesso a serviços de saúde para populaçóes específicas, principalmente na assistência à saúde mental e saúde da pessoa com deficiência.

Ainda segundo as mesmas autoras, a incorporação de terapeutas ocupacionais no município de São Paulo entre os anos de 1989 e 1993, por exemplo, esteve 
intimamente ligada aos movimentos da reforma sanitária, reforma psiquiátrica e da luta antimanicomial e das pessoas com deficiência. Em 1989, a Secretaria Municipal de Saúde, impulsionada pelo recém-criado programa de saúde mental, realizou o primeiro concurso municipal para a categoria e 45 terapeutas ocupacionais foram contratados. Em 1992, havia 241 terapeutas ocupacionais atuando em diversos serviços e em diferentes regióes do município.

Dessa forma, terapeutas ocupacionais em São Paulo consolidaram sua presença em serviços públicos de saúde como hospitais dia, centros de convivência e cooperativas, enfermarias e emergências psiquiátricas, hospitais gerais e unidades básicas de saúde (UBS). Nesses últimos, os terapeutas ocupacionais faziam parte de equipes de saúde mental e atendiam outras populaçóes, como idosos, crianças e jovens, vinculando-se, também, a atividades das equipes de saúde, como nas ações de educação em saúde, acompanhamento de crianças, entre outras (OLIVER; BARROS; LOPES, 2005; LOPES, 1999).

As populações atendidas nesse momento foram especialmente pessoas com deficiências físicas, com dificuldades de aprendizado, com sequelas neurológicas e pessoas que apresentavam sofrimento psíquico, mas também foram relatados atendimentos a crianças com atraso no desenvolvimento neuropsicomotor, bebês de risco e queimados de segundo e terceiro graus (OLIVER; BARROS; LOPES, 2005).

Mais recentemente, o Ministério da Saúde, através da portaria GM no. 154 de janeiro de 2008, criou os Núcleos de Apoio à Saúde da Família (NASF), que são equipes compostas por profissionais de diferentes áreas de conhecimento, inclusive de terapia ocupacional, para atuar em conjunto com os profissionais das equipes de saúde da família, com o objetivo de ampliar o escopo e a resolutividade de atenção aos usuários (BRASIL, 2010a). Tal fato possibilitou a inserçáo dos terapeutas ocupacionais na APS em nível nacional, visto que até então essa inserção acontecia em nível local, com experiências pontuais dependentes das políticas locais e regionais de estabelecimento de prioridades de atenção e de contratação de profissionais.

O NASF é composto por áreas estratégicas, para as quais foram traçadas diretrizes e principais açóes a serem desenvolvidas. Tais açóes devem ser realizadas a partir das necessidades de saúde da população de um território em particular, bem como das características da equipe. As áreas estratégicas são: saúde mental; reabilitação e saúde integral da pessoa idosa; alimentaçáo e nutrição; assistência farmacêutica; intersetorialidade, redes sociais e participação cidadá; atenção integral à saúde da criança e do adolescente; atenção integral à saúde da mulher; práticas integrativas e complementares e práticas corporais e atividades físicas. Dentre as áreas estratégicas foram destacadas algumas populações e açóes descritas em documento norteador do Ministério da Saúde (BRASIL, 2010a):

\section{- Saúde Mental}

- Ampliação e qualificação do cuidado às pessoas em sofrimento psíquico nos serviços com base no território;

- Apoio às equipes de saúde da família no trabalho com pacientes em situação de sofrimento psíquico;

- Ativação da rede de saúde mental, com a integração de serviços setoriais (da saúde) e intersetoriais;

- Continuidade do cuidado e

- Priorização no atendimento de situaçóes de maior grau de vulnerabilidade e risco social.

\section{- Reabilitaçáo e saúde integral da pessoa com deficiência e idosos}

- Inclusão de açóes de reabilitaçáo na APS;

- Integração do modelo clínico e social, perspectiva de responsabilidade coletiva e compromisso com a inclusão social;

- Promoção à saúde, prevenção de agravos e deficiências, com importante participaçáo nas campanhas de vacinação;

- Promoção do protagonismo da pessoa com deficiência e sua família;

- Redução de incapacidades, melhora da funcionalidade, acesso a tecnologias de ajuda e acessibilidade;

- Promoçáo da participação comunitária e acesso a direitos sociais;

- Apoio na inclusão escolar de crianças com deficiências;

- Promoção do envelhecimento saudável, bem como de açóes de combate à violência contra o idoso; e

- Orientaçóes quanto à rotina saudável, prevenção de quedas e estratégias para a administraçáo correta dos medicamentos.

\section{- Saúde da criança e do adolescente}

- Promoção da saúde integral da criança, com incentivo ao aleitamento materno e atenção à saúde do recém-nascido;

- Prevenção de violência e promoçáo da cultura da paz;

- Investigação de óbitos infantis; 
- Vigilância ao desenvolvimento infantil, orientação para estimulação da criança;

- Apoio às equipes de saúde da família na abordagem de crianças com doenças crônicas, patologias graves, em sofrimento psíquico e com deficiências;

- Realização de ações em escolas, creches e outras instituiçốes que atendam o público infantil;

- Promoção de espaços de empoderamento e participação comunitária da juventude; e

- Orientaçôes quanto à saúde sexual, projetos de vida e profissionais.

\section{- Saúde da mulher}

- Prevenção do câncer de colo e da mama;

- Planejamento familiar, pré-natal, saúde sexual;

- Redução de doenças sexualmente transmissíveis e aids;

- Atenção às doenças crônicas como hipertensão arterial sistêmica (HAS) e diabetes mellitus;

- Atenção ao sofrimento psíquico, uso de álcool e drogas;

- Situação de vulnerabilidade e risco social (violência doméstica, condições de trabalho que podem provocar adoecimento); e

- Promoçáo de açốes que tenham como resultado o empoderamento da mulher e o enfrentamento de situaçóes de opressão.

A atenção a essas e outras populações no cenário da APS indica a necessidade de desenvolvimento de açôes complexas, que envolvem a família, os recursos do território e estấo diretamente relacionadas ao modo de viver e trabalhar da população atendida que, por sua vez, compóe os determinantes sociais que influenciam os processos de saúde e doença dos indivíduos e das coletividades, tema que foi amplamente discutido entre os profissionais participantes do debate.

\section{Desafios na composição das linhas de cuidado e as condições de vida da população atendida pela terapia ocupacional}

Como já foi citado, as falas na roda de discussão apontaram para uma série de problemáticas relacionadas à dificuldade da população no acesso a serviços de Atenção Primária à Saúde e a fragilidade na constituição das linhas de cuidado integral à saúde. Esses aspectos também foram discutidos em estudos sobre o acesso de pessoas com deficiência na rede de serviços da APS (ROCHA; SOUZA, 2011; CASTRO et al., 2011) e em estudos sobre os desafios do cuidado a pessoas em sofrimento psíquico na Estratégia de Saúde da Família (ARCE; SOUSA; LIMA, 2011).

Os profissionais também indicaram outras populaçóes que têm apresentado dificuldades para acessar a rede de assistência à saúde como trabalhadores, pessoas em situação de rua e a população indígena, conforme acima mencionado.

Segundo a percepçáo dos profissionais, os trabalhadores enfrentam dificuldades no acesso aos serviços principalmente devido ao horário de funcionamento das Unidades Básicas de Saúde (UBS) que, em sua maioria, não contemplam atendimentos noturnos, nem em finais de semana. Essa população, que poderia também se beneficiar da assistência do terapeuta ocupacional, está impossibilitada de realizar o seu cuidado à saúde nesses serviços.

Quanto às pessoas em situação de rua, Varanda e Adorno (2004), em um estudo sobre a saúde dessa população, discutiram que essas pessoas, por diversos motivos, pouco procuram os serviços de saúde, enquanto suportam uma série de sintomas agravados, também, pela precariedade da condição de permanência nas ruas. Para os autores torna-se urgente reconhecer os diferentes problemas de acesso, as questôes regionais, culturais e outras que se relacionam com a saúde para garantir a assistência a esse segmento da população. No campo da terapia ocupacional, Ghirardi et al. (2005) relataram uma intervenção com moradores de rua a partir de uma experiência de cooperativismo. Tal estudo promoveu a reflexão sobre a contribuição dos profissionais na possibilidade de resgate da condição de sujeitos e da criação de políticas públicas voltadas para a população em situação de rua.

Macedo (2010) apresentou estudo sobre jovens indígenas Guarani e, dentre outros temas, destacou as contradiçóes presentes no campo da saúde. $\mathrm{O}$ estudo indicou a importância da existência de um serviço básico de saúde na região de moradia dessa população, bem como a presença, ainda que frágil, de uma rede de serviços de atendimento à saúde (ambulatórios e hospitais), porém constatou-se “[...] a grande necessidade do diálogo intercultural para melhorar a atençáo oferecida pelos serviços de saúde [...]" (p. 116).

Assim, levando-se em conta os princípios de universalidade, integralidade e equidade do sistema de saúde do país, tornou-se um desafio a implementação 
de políticas públicas que garantam uma assistência à saúde integral e de qualidade e que respondam às especificidades de cada população, sejam elas trabalhadores, pessoas com deficiências, pessoas em sofrimento psíquico ou em situação de rua. Nesse sentido, conhecer as necessidades de saúde da população, bem como sua forma de viver e de produzir tem sido crucial para a definição de estratégias específicas na produção de assistência.

Quando os participantes do grupo se referiram à população atendida, sobressaíram em sua fala questôes relacionadas às próprias condiçôes de vida, marcadas pela pobreza e por processos de exclusão e de extrema vulnerabilidade social. Essas questóes trazem repercussóes ao trabalho cotidiano do profissional e das equipes que, muitas vezes, se sentem despreparadas e não apoiadas objetivamente pelos serviços para lidar com as demandas apresentadas.

As condiçôes de vida repercutem nas necessidades de saúde, compreendidas como necessidade de reprodução social, produzidas a partir de uma determinada realidade social e que são marcadas, nesse caso, por relaçóes desiguais de acesso ao que pode vir a satisfazer as necessidades (CAMPOS; BATAIERO, 2007). Nesse contexto, o processo saúde-doença e as necessidades de saúde se relacionam às diferentes formas de viver e trabalhar de uma população que vivencia determinado contexto social (EGRY; OLIVEIRA, 2008).

Tal complexidade também foi discutida nos estudos de Pimentel, Costa e Souza (2011) e de Aoki, Oliver e Nicolau (2011), os quais apontaram que as demandas apresentadas pelas pessoas com deficiência à atenção territorial em saúde não dizem respeito apenas a necessidades no campo da deficiência mas também estão relacionadas a dificuldades financeiras, condições precárias de vida e a falta de acesso a direitos sociais. Nesse sentido, é necessário que o olhar do terapeuta ocupacional esteja atento a questôes relacionadas à condição de vida e trabalho, além das questôes específicas demandadas pela populaçáo e pelos serviços.

A compreensão acerca da complexidade das condiçôes, necessidades e demandas de saúde não tem sido suficiente para que os profissionais tenham as ferramentas necessárias para construir as estratégias assistenciais de sua área profissional específica, e também para as equipes. Como disse uma participante, diante de relatos de casos marcados por situaçóes de pobreza, vulnerabilidade social e violação dos direitos humanos: "A complexidade das situaçôes não pode ser vista como algo que paralisa, mas sim que instiga".
Nesse sentido, os profissionais vêm buscando formas de responder às complexas demandas que surgem no cotidiano dos serviços de saúde nos quais atuam. A organizaçáo dos processos de trabalho a partir das diretrizes das linhas de cuidado, através da escuta e da reflexão sobre as necessidades dos sujeitos, priorizando o contato entre profissionais, usuários e a realidade do contexto social vivido, foi apresentada pelos participantes como estratégia fundamental para lidar com as necessidades de saúde da população atendida.

Pode-se chamar de linha de cuidado o percurso que um sujeito realiza na rede de saúde, incluindo serviços não necessariamente do setor da saúde como, por exemplo, aqueles oferecidos por entidades comunitárias e de assistência social (FRANCO; MAGALHÃES JUNIOR, 2003).

Malta e Merhy (2010) apontam que, a partir da entrada em um serviço de saúde, abre-se um percurso que se estende, conforme as necessidades do beneficiário, por serviços de atenção básica, de apoio diagnóstico e terapêutico, especialidades, atenção hospitalar, entre outros. Os autores consideram que as linhas de cuidado devem ser implicadas sobre duas perspectivas: a micropolítica e a macropolítica.

Em relação à micropolítica, as práticas cotidianas são realizadas por meio das trocas de saber entre o profissional e o usuário, através das negociaçôes que possibilitem o restabelecimento da autonomia. Os autores apontam como fatores constituintes de uma linha de cuidado na perspectiva da micropolítica: a atuação da equipe na coordenação do cuidado; a vinculação e responsabilização do cuidador; a busca da produção da autonomia do usuário; e a criação de projetos terapêuticos singulares, ou seja, é fundamental a construção de quais caminhos trilhar em relação ao cuidado à saúde em conjunto com a equipe e o usuário (MALTA; MERHY, 2010).

No âmbito da macropolítica está a compreensão de que as linhas do cuidado dependem da determinaçáo e apoio dos gestores para atuaçáo nos determinantes sociais, garantindo articulaçóes intersetoriais e atuando na regulação do sistema, no financiamento de ações, na rede de serviços e na organização da vigilância e das informaçôes em saúde.

Em relação à organização da rede de serviços, os autores apontam que a integralidade só pode ser obtida em rede e que cada serviço deve ser repensado como um componente fundamental, como uma estação no circuito que cada indivíduo percorre para obter a atençáo que precisa. Cabe aos profissionais e gestores o desafio de conectar essa rede da forma mais adequada possível. Embora seja um conceito 
simples, as linhas de cuidado têm se apresentado de difícil consecução (MALTA; MERHY, 2010), como apontaram também os participantes do grupo de discussão, que relataram inúmeros problemas na continuidade do cuidado, principalmente no que se refere ao acesso à insuficiente rede de referência e contrarreferência dos serviços de saúde e demais serviços territoriais.

Ou seja, a organização e ativação da rede assistencial ainda é um desafio para as equipes de NASF e profissionais que atuam na APS. Nesse contexto, considerando a formação do terapeuta ocupacional como agente político de transformação social (MALFITANO, 2005), esse teria um papel fundamental também na articulação da rede de assistência, trabalho integrado com outros profissionais das equipes de saúde.

\section{Prática generalista do terapeuta ocupacional e a inserção em equipes interdisciplinares}

Os profissionais reconheceram que há necessidade de atenção a populaçôes com demandas específicas, porém também foi colocada a necessidade de que o terapeuta ocupacional esteja preparado para o desenvolvimento de uma prática assistencial mais generalista, conforme as demandas que se apresentarem nos territórios de abrangência dos serviços.

Na discussão, uma participante colocou que " $a s$ pessoas não querem ser atendidas por especialistas, elas querem que alguém as ouça", se referindo à importância do acolhimento e do vínculo no momento de planejar a intervenção, além de fazer uma crítica à intervenção de saúde focada na especificidade clínica e diagnóstica, normalmente centrada na figura do médico.

Também se discutiu no grupo que em alguns serviços de Atenção Primária à Saúde a organização do trabalho do terapeuta ocupacional tem se estabelecido pela divisão entre as áreas de atuação em saúde mental ou reabilitação, o que para os participantes se mostrou um equívoco diante da diversidade da população que tem solicitado assistência nas unidades básicas de saúde.

Nesse sentido é possível considerar que na APS, o profissional de terapia ocupacional deve ter uma atuação não fragmentada, pautada nas ideias da clínica ampliada. Essas buscam construir sínteses singulares tensionando os limites de cada matriz disciplinar, ampliando os objetos de trabalho para além da doença, do diagnóstico e das intervençôes fechadas e colocando em primeiro plano a situação real do trabalho em saúde vivida pelo sujeito e que deve ser construída e compartilhada com o próprio usuário, bem como com todos os profissionais que trabalham com ele (BRASIL, 2010a).

Por outro lado, a atuação do profissional pode ter como base uma prática generalista que não reduza a experiência do cuidado centrado apenas no diagnóstico e sim em formas de construção de resistência diante dos processos de exclusão social, como aponta Lima (2003):

Assim, tendo acompanhado a construção histórica de grupos populacionais que são alvo de práticas disciplinares, nos voltamos agora para a tentativa de pensar esses grupos não de modo a categorizá-los, mas buscando encontrar traçóes e linhas que os atravessam e que possam ser acompanhados e percorridos na construção de formas de resistência diante dos processos de exclusão [...] (p. 67)

Essa prática generalista está contextualizada no saber específico da terapia ocupacional que, conforme aponta Malfitano (2005), tem um núcleo de saber bastante potente para debater e atuar em pontos entre o micro e o macrossocial, ou seja, o individual e o coletivo, o técnico e o político, considerando seu olhar para o cotidiano das pessoas atendidas e afirmando que essa prática deve estar presente no cotidiano do profissional.

Outra polêmica relacionada ao papel e contribuição da terapia ocupacional para construção de uma APS não seletiva e mais contextualizada diz respeito às divergências entre as açóes que deveriam ser desenvolvidas com as populaçóes na atenção primária ou em outros níveis de complexidade da atençáo à saúde que têm tecnologias e recursos diferentes.

A assistência a essas populaçóes deve ocorrer a partir do que pode ser chamado de "atenção terapêutica ocupacional básica”, que é específica mas não especializada. Isso quer dizer que a especificidade da profissão não é perdida, ao contrário, o raciocínio terapêutico é mantido e potencializado o tempo todo. O profissional náo pode "despir-se" do mesmo, pois este tem muito a contribuir para a equipe, para os usuários e para o território. O que não se pode confundir é a atenção específica da profissáo com a especializada, realizada em outros níveis de atenção (SOUZA, 2011).

Ainda num plano de atuação profissional generalista, os participantes evidenciaram também que o terapeuta ocupacional tem atuado amplamente 
na área da promoçáo de saúde e prevenção de doenças com açôes relacionadas a esses âmbitos em todos os momentos de atuaçáo, nos atendimentos grupais, individuais, nas visitas domiciliares e naquelas açóes intersetoriais e de âmbito comunitário.

Como exemplo, podem-se citar os cuidados oferecidos à população que está na iminência do adoecimento - como no caso do sofrimento psíquico ou da hipertensão arterial sistêmica e/ou diabetes. A intervençâo tem sido realizada para que o adoecimento não seja instalado (prevenção primária, realizada, por exemplo, através da participação da TO nos grupos de educação em saúde envolvendo pessoas com hipertensão arterial e diabetes). $\mathrm{O}$ profissional pode atuar também na prevenção secundária de agravos produzidos por determinado tipo de sofrimento como, por exemplo, na atuação com crianças com deficiência ou com pessoas com hanseníase, promovendo açôes tanto para a ampliação das capacidades como para a inclusão escolar, no trabalho e para o impedimento da aquisição de incapacidades ou desvantagens (ORGANIZAÇÃO..., 2003). O terapeuta ocupacional também pode realizar açôes no âmbito da prevenção terciária, minimizando o agravamento e sofrimento de acamados ou de pessoas com patologias em estágio avançado, promovendo qualidade de vida também para o cuidador e demais familiares.

Outro aspecto fundamental do cuidado na atenção primária é o trabalho em equipe, estratégia elencada pelo Ministério da Saúde como um dos principais pontos para a organizaçáo de processos de trabalho e caracterizada como:

[...] açôes clínicas compartilhadas para uma intervenção multidisciplinar, com trocas de saberes, capacitação e responsabilidades mútuas, gerando experiência para ambos profissionais envolvidos [...] (BRASIL, 2010a, p. 20).

$\mathrm{Na}$ tentativa de orientar o trabalho dos profissionais no NASF, o Ministério da Saúde definiu as atribuiçóes gerais dos trabalhadores que compóem a equipe. Nelas há indicação da necessidade de estabelecer espaços rotineiros de discussão e planejamento coletivos (com a equipe NASF, equipe de saúde e comunidade) para:

- Definir o público alvo das açôes;

- Identificar açôes e práticas a serem adotadas;

- Realizar açôes intersetoriais (articulação com demais políticas sociais);

- Promover a gestáo integrada e a participaçáo social dos usuários por meio dos conselhos locais de saúde;
- Avaliar as açóes;

- Realizar atividade de educação em saúde; e

- Desenvolver projetos terapêuticos considerando as açôes interdisciplinares e a responsabilidade compartilhada (BRASIL, 2010a).

Embora o trabalho em equipe tenha sido discutido como uma ferramenta primordial para promover assistência às populaçóes que vivenciam situações tão complexas, este tema levantou muitas contradiçóes durante sua reflexão.

Os participantes relataram a ocorrência de conflitos no âmbito do relacionamento interprofissional, além de dificuldades de as equipes (NASF e Equipe Saúde da Família) coletivizarem as ações e identificarem problemas para a construçáo de projetos comuns.

A falta de formação dos profissionais para o trabalho em equipe e para uma abordagem mais integral à saúde foi uma das questóes apontadas pelos participantes como dificultadora do processo de construção da assistência na Atenção Primária à Saúde. Tal discussão deve apresentar-se de modo mais consistente na qualificação dos trabalhadores, bem como nos currículos da graduaçáo dos terapeutas ocupacionais, que ainda concentram-se em áreas de especialidades.

Nesse campo de contradiçóes, o terapeuta ocupacional foi considerado um profissional potente na articulação da rede assistencial, na construçáo de trabalhos coletivos, bem como no cuidado da própria equipe dos profissionais de saúde e em especial dos Agentes Comunitários de Saúde. Porém ficaram claras as limitaçóes do profissional e a urgência de se pensar em estratégias para garantir a efetividade das linhas de cuidado. Como disse uma participante:

\section{Dentro da linha de cuidado náo é o terapeuta ocupacional que tem de resolver tudo. Há necessidade de dividir com outros profissionais e outros serviços. O terapeuta ocupacional deve participar da linha de cuidado, não tomar conta dela.}

\section{Considerações finais}

A realizaçáo de um debate coletivo sobre as populaçóes atendidas pela terapia ocupacional na Atenção Primária à Saúde em um simpósio apresentou um panorama das práticas profissionais bastante amplo e desafiador. Profissionais e estudantes puderam realizar trocas de experiências e refletir sobre problemas comuns e específicos que têm causado inquietaçóes no cotidiano do trabalho. $\mathrm{O}$ cenário nacional atual de ampliação da inserção 
da categoria na Atenção Primária à Saúde através do NASF torna o tema extremamente relevante e pode auxiliar na construção da prática profissional do terapeuta ocupacional.

Esse profissional, juntamente com a equipe interdisciplinar, tem atuado no campo da prevenção, promoção, assistência e reabilitação da saúde de diversas populaçôes, desde as mais tradicionais (relacionadas à saúde mental, à reabilitação, ao atendimento à infância e ao idoso) a outras populaçóes, como pessoas em situação de rua, indígenas e trabalhadores.

Ainda se observam dificuldades de acesso aos serviços de Atenção Primária à Saúde para as populaçóes citadas, bem como a dificuldade de articulação dos serviços de referência e contrarreferência do sistema de saúde e demais recursos intersetoriais. Nesse sentido, a ativação de uma linha de cuidado que garanta atendimento integral aos indivíduos ainda é um desafio para o sistema de saúde e para os profissionais, assim como a constituição das redes de atençáo à saúde, proposta recente apresentada pelo Ministério da Saúde (BRASIL, 2010b).

A complexidade das condiçóes de vida e das necessidades de saúde das populaçóes atendidas na APS, marcadas por pobreza e situações de vulnerabilidade social, têm revelado também a importância de o terapeuta ocupacional buscar novas ferramentas de trabalho, além de aperfeiçoamento teórico e metodológico, para compreender e participar das iniciativas de intervenção sobre tal realidade. Faz-se necessária a mobilização de distintos saberes, tanto do núcleo específico da categoria como do próprio campo da saúde coletiva. Dessa forma, a realidade da APS tem exigido um profissional generalista, comprometido com a continuidade de sua formação profissional e capaz de atuar reflexivamente também de forma interdisciplinar e intersetorial.

Outro aspecto que chamou a atenção e necessita ser superado, e que por isso é reforçado nestas consideraçóes, se refere à fragmentação da atuação do terapeuta ocupacional nas áreas específicas de reabilitação e saúde mental que tem acontecido em alguns serviços pelo país. Essa fragmentação fere a necessidade de atuação generalista do profissional, fundamentada nas necessidades e demandas dos diferentes usuários que surgem no cotidiano dos serviços, e ainda pode empobrecer a prática do terapeuta ocupacional e a dos demais profissionais da equipe, que passam a não perceber e reconhecer as inúmeras necessidades de atenção colocadas pelas demandas de saúde das populaçôes dos territórios, bem como as possibilidades de atuação profissional em um contexto amplo de compreensão da saúde.

Para superação dessa fragmentação é necessário fundamentalmente que os serviços de APS, em geral, e os NASF, em particular, também possam refletir sobre as responsabilidades que têm para a construção do acesso e oferta da atenção integral aos diferentes grupos populacionais de sua área de abrangência. Ou seja, a atenção deverá se configurar a partir da complexidade das condiçóes dos usuários e não das possibilidades ou atribuiçóes dos profissionais das equipes.

Torna-se importante, também, evidenciar a necessidade de formaçáo dos terapeutas ocupacionais para atuação nesse contexto, já que em muitos currículos de graduação as diretrizes da Atenção Primária à Saúde, as necessidades de atenção à saúde de diferentes grupos da população, ou mesmo a atuação interdisciplinar são pouco exploradas. Portanto, são necessários investimentos tanto na formação dos futuros terapeutas ocupacionais para atuação na Atenção Primária à Saúde, com ênfase na Estratégia de Saúde da Família, como na formação dos profissionais que já atuam nesse cenário.

\section{Referências}

AOKI, M.; OlIVER, F. C.; NICOLAU, S. M. Consideraçóes acerca das condiçóes de vida das pessoas com deficiência a partir de um levantamento em uma unidade básica de saúde de um bairro periférico do município de São Paulo. O Mundo da Saúde, São Paulo, v. 35, n. 2, p.169-178, 2011. Disponível em: <http:// www.saocamilo-sp.br/pdf/mundo_saude/84/169-178. pdf $>$. Acesso em: 12 jul. 2012.

ARCE, V. A. R.; SOUSA, M. F.; LIMA, M. G. A práxis da Saúde Mental no âmbito da Estratégia Saúde da Família: contribuiçôes para a construçấo de um cuidado integrado. Physis: Revista de Saúde Coletiva, Rio de Janeiro, v. 21 , n. 2 , p. $541-560,2011$. http://dx.doi.org/10.1590/ S0103-73312011000200011

BRASIL. Ministério da Saúde. Secretaria de Atenção à Saúde. Departamento de Atençáo Básica. Politica nacional de atenção básica. Brasília: Ministério da Saúde, 2006.

BRASIL. Ministério da Saúde. Secretaria de Atenção à Saúde. Departamento de Atenção Básica. Diretrizes do NASF: Núcleo de Apoio a Saúde da Família. Brasília: Ministério da Saúde, 2010a. 152 p. (Cadernos da atenção básica).

BRASIL. Ministério da Saúde. Portaria no 4.279, de 30 de dezembro de 2010. Estabelece diretrizes para a organizaçáo da Rede de Atenção à Saúde no âmbito do Sistema Único de Saúde - SUS. Diário Oficial da República Federativa do Brasil, Poder Executivo, Brasília, DF, 31 dez. 2010b. Seçấo 1. Disponível em <http://portal.saude.gov.br/ 
portal/arquivos/pdf/portaria4279_docredes>. Acesso em: 18 jul. 2012.

CAMPOS, C. M. S.; BATAIERO, M. O. Necessidades de saúde: uma análise da produção científica brasileira de 1990 a 2004. Interface: Comunicacao, Saude, Educacao, Botucatu, v. 11, n. 23, p. 605-18, set./dez. 2007. http:// dx.doi.org/10.1590/S1414-32832007000300014

CASTRO, S. S. et al. Acessibilidade aos serviços de saúde por pessoas com deficiência. Revista de Saúde Pública, São Paulo, v. 45, n. 1, p. 99-105, out. 2011. http://dx.doi. org/10.1590/S0034-89102010005000048

EGRY, Y.; OLIVEIRA, M. A. C. Marcos teóricos e conceituais de necessidades: In: EGRY, Y. (Org.). As necessidades em saúde na perspectiva de atenção básica: Guia para pesquisadores. São Paulo: Dedone, 2008. p. 31-38. FRANCO, T. B.; MAGALHÂES JUNIOR, H. A integralidade e as linhas de cuidado. In: MERHY, E. E. et al. O Trabalho em Saúde: Olhando e Experienciando o SUS no Cotidiano. São Paulo: Hucitec, 2003. p. 125-133.

GHIRARDI, M. I. G. et al. Vida na rua e cooperativismo: transitando pela produçáo de valores. Interface: Comunicacao, Saude, Educacao, Botucatu, v. 9, n. 18, p. 601-10, set./dez. 2005. http://dx.doi.org/10.1590/ S1414-32832005000300014

GIOVANELLA, L.; MENDONÇA, M. H. M. Atenção Primaria à Saúde. In: GIOVANELLA, L. (Org.). Políticas e Sistema de Saúde no Brasil. Rio de Janeiro: Editora Fiocruz, 2008. p. 575-625.

LIMA, E. M. F. A. Desejando a diferença: consideraçōes acerca das relaçôes entre os terapeutas ocupacionais e as populaçôes tradicionalmente atendidas por estes profissionais. Revista de Terapia Ocupacional da Universidade de São Paulo, São Paulo, v. 14, n. 2, p. 64-71, maio/ago. 2003.

LOPES, R. E. Cidadania, politicas publicas e terapia ocupacional no contexto das açōes de saúde mental e saúde da pessoa portadora de deficiência no município de São Paulo. 1999. 536 f. Tese (Doutorado em Educação)Universidade Estadual de Campinas, Campinas, 1999.

MACEDO, M. D. C. Jovens entre culturas: itinerários e perspectivas de jovens Guarani entre a aldeia Boa Vista e a cidade de Ubatuba. 2010. 328 f. Dissertaçáo (Mestrado em Fisioterapia e Terapia Ocupacional)-Faculdade de Medicina, Universidade de Sáo Paulo, 2010.
MALFITANO, A. P. S. Campos e núcleos de intervenção na terapia ocupacional social. Revista de Terapia Ocupacional da Universidade de São Paulo, São Paulo, v. 16, n. 1, p. 1-8, jan./abr. 2005.

MALTA, D. C.; MERHY, E. E. O percurso da linha do cuidado sob a perspectiva das doenças crônicas não transmissíveis. Interface: Comunicacao, Saude, Educacao, Botucatu, v. 14, n. 34, p. 593-606, set. 2010. http://dx.doi. org/10.1590/S1414-32832010005000010

OLIVER, C. O.; BARROS, D. D.; LOPES, R. E. Estudo sobre a incorporaçáo da terapia ocupacional no contexto das açóes de saúde mental e saúde da pessoa com deficiência no Município de São Paulo entre 1989 e 1993. Revista de Terapia Ocupacional da Universidade de São Paulo, São Paulo, v. 16, n. 1, p. 31-39, jan/abr. 2005.

ORGANIZAÇÃO MUNDIAL DA SAÚDE - OMS. Centro Colaborador da Organização Mundial da Saúde para a Família de Classificaçôes Internacionais. CIF: Classificação Internacional de Funcionalidade, Incapacidade e Saúde. [Coordenação da traduçấo de Cassia Maria Buchalla]. São Paulo: EdUSP, 2003.

PIMENTEL, A. M.; COSTA, M. T. B.; SOUZA, F. R. Terapia Ocupacional na Atenção Básica: a construção de uma prática. Revista de Terapia Ocupacional da Universidade de São Paulo, São Paulo, v. 22, n. 2, p. 110-116, maio/ ago. 2011.

ROCHA, E. F.; SOUZA, C. C. B. X. Terapia Ocupacional em reabilitação na Atenção Primária à Saúde: possibilidades e desafios. Revista de Terapia Ocupacional da Universidade de São Paulo, São Paulo, v. 22, n. 1, p. 36-44, jan./abr. 2011.

SOUZA, F. R. A inserção dos terapeutas ocupacionais nos Núcleos de Apoio à Saúde da Família, em Fortaleza, Ceará. 2011. 45 f. Monografia (Residência Multiprofissional em Saúde da Família e Comunidade)-Sistema Municipal de Saúde Escola, Secretaria Municipal de Saúde, Fortaleza, 2011.

STARFIELD, B. Atenção primaria equilibrio entre necessidades de saúde, serviços e tecnologia. Brasília: UNESCO; Ministério da Saúde, 2002.

VARANDA, W.; ADORNO, R. C. F. Descartáveis urbanos: discutindo complexidade da população de rua e o desafio para políticas de saúde. Saúde e Sociedade; São Paulo, v. 13, n. 1, p. 56-69, jan./abr. 2004.

\section{Contribuição dos Autores}

Todas as autoras foram responsáveis pela concepção e redação do presente trabalho, assim como pela revisão e aprovação final para publicação. 